\title{
Um diálogo entre a teoria ator-rede e a proposta artística de Hélio Oiticica: o que a psicologia tem a ver com isso?
}

\section{A dialogue between the actor-network theory and the artistic proposal of Helio Oiticica: what psychology has to do with it?}

\section{Un diálogo entre la teoría actor-red y la propuesta artística de Helio Oiticica: que tiene la psicología que ver con esto?}

\author{
Debora Emanuelle Nascimento Lomba* \\ Universidade do Estado do Rio de Janeiro - UERJ, Rio de Janeiro, Rio de Janeiro, \\ Brasil
}

\begin{abstract}
RESUMO
O presente trabalho é uma releitura da monografia "Eu sou uma obra de arte, o museu é um mundo", cujas questões trabalhadas envolvem a proposta artística de Hélio Oiticica, bem como sua aproximação com uma maneira alternativa de pensar a psicologia, a saber, a teoria ator-rede (TAR). Com isso, temos tanto um trabalho que une psicologia e arte, como um trabalho que problematiza as práticas em psicologia. Dessa forma, serve de apoio para esta discussão, uma bagunça na maneira de pensar e fazer psicologia, totalmente embasadas pelos autores da TAR e dialogando com Hélio Oiticica. Uma discussão que inclui diversos atores e faz compor uma proposta política diferente da lógica dominante na psicologia.
\end{abstract}

Palavras-chave: teoria ator-rede, artes, psicologia, psicologia social, Hélio Oiticica.

\begin{abstract}
This paper aims to discuss some questions worked in the end-of-course monograph "Eu sou uma obra de arte, o museu é um mundo", which involved Helio Oiticica artistic proposal and the aproach of his work with an alternative way of thinking psychology: Actor-Network Theory (ANT). So we have a work which unites psychology and artes and discuss practices in psychology. Thus to support this discussion we work making a mess in the way of think and do psychology with the aport of ANT's authors dialoguing with Helio Oiticica. This discussion includes a lot of actors and compose a politic proposal different of dominating logic in psychology.

Keywords: actor-network theory, arts, psychology, social psychology, Hélio Oiticica.

\section{RESUMEN}

El presente trabajo es una lectura de la monografía "Yo soy una obra de arte, el museo es un mundo", cuyas cuestiones trabajadas envuelven la propuesta de artística de Helio Oiticica, bien como su aproximación con una manera alternativa de pensar la psicología, o sea, la teoría ator-rede (TAR).
\end{abstract}


Con eso, tenemos tanto un trabajo que une psicología y arte como un trabajo que problematiza las practicas en psicología. De esta forma, sirve de apoyo para esta discusión, un desorden en la forma de pensar y hacer la psicología, totalmente basadas por los autores de la TAR dialogando con Helio Oiticica. Una discusión que incluye diversos actores y compone una propuesta política diferente a la lógica dominante de la psicología.

Palabras-clave: teoría ator-rede, arte, psicología, psicología social, Hélio Oiticica.

\section{Tecendo uma colcha de retalhos}

O presente trabalho pretende problematizar a incorporação da psicologia em espaços pouco comuns e uma certa dificuldade em vêla habitar estes novos campos. Para servir de base para esta discussão, recupero questões abordadas na monografia "Eu sou uma obra de arte, o museu é um mundo". Este Trabalho de Conclusão de Curso (TCC) objetivou discutir a proposta do grande artista brasileiro Hélio Oiticica, bem como traçar um paralelo dessa, com uma maneira alternativa de pensar a Psicologia, segundo estudos de determinados autores da teoria ator-rede (TAR). Dessa forma, as linhas deste texto servirão de base para que uma colcha de retalhos seja montada a partir dos trabalhos de Hélio Oiticica e dos autores da TAR. Uma construção que só será possível dada a proximidade de proposições encontradas nestes.

Ao longo do processo de construção da monografia, coube destacar uma pergunta recorrente, por parte de leigos e acadêmicos, convocando para esse diálogo uma das questões mais pertinentes e envolventes do trabalho em questão, ganhando um destaque especial para que a problematização tivesse o seu espaço de discussão. Pergunta esta que, no presente artigo, torna-se também o foco fundamental para discutir os assuntos a serem abordados: onde está a Psicologia?

Ao optar pela escrita deste tema, muitos desafios foram apresentados, desde o planejamento à construção, como também da busca por textos à participação de atividades envolvendo a proposta artística de Oiticica. E como dito acima, muitos foram os questionamentos quando interpelada pelo tema de monografia. Houve um certo desconforto por parte de alguns acadêmicos, assim como uma certa desconfiança por parte dos leigos, que indagavam se esta era mesmo uma discussão cabível na área da psicologia. Os mais audaciosos perguntavam se não era um trabalho para o campo das artes e se não seria melhor optar por outro tema. Como avaliado por um professor que leu parte da monografia ainda em construção, havia paixão e sede por questionamentos, por isso o abandono da ideia não fazia sentido. 
Sendo assim, com as mangas já suspensas, as mãos tinham de ir à obra, neste caso, literalmente. Felizmente, na mesma época da construção da monografia, foi realizada uma exposição em alguns museus do Centro do Rio de Janeiro, bem como algumas intervenções urbanas, o que possibilitou um contato direto com o trabalho e com as ideias do artista, haja vista que uma série de atividades e palestras aconteceram na ocasião. Com isso, paralelo a leitura de textos que serviam de base teórica, muitas experiências nestes locais em conjunto com as obras, possibilitaram a feitura e a conclusão da monografia, que hoje inspira a escrita deste artigo.

Durante o processo de escrita, em conversa com meu orientador, Ronald Arendt, percebi que a origem deste trabalho não se deu a partir do encontro com Hélio Oiticica, mas do encontro com os autores da teoria ator-rede, que possibilitaram o vislumbre de uma psicologia que começava a fazer sentido para mim. Uma Psicologia comprometida com uma proposta alternativa aos caminhos já marcados e trilhados pela visão dominante de Psicologia, ou seja, envolvida com os postulados de uma ciência moderna. Uma aposta em uma Psicologia cuja busca pela clareza, pureza e generalizações, tão almejadas pela modernidade, não tem ressonâncias em sua prática, entretanto, com uma mesma preocupação com o rigor e a fundamentação de suas propostas. Esta sede por uma psicologia que não comungasse com os princípios modernos, é encontrada em diálogo com os escritos de Latour (1994; 2000; 2008). Ao apontar que tais postulados modernos não satisfazem o que vislumbro, enquanto teoria e prática, me apoio nas contribuições de Latour (ibidem) para apostar num referencial preocupado com os processos muito mais do que com o estabelecimento de padrões e generalizações. Priorizar o foco nas relações ao invés de uma tentativa de revelar um saber sobre o que se pretende estudar, haja vista que, Latour não acredita na existência de um mundo "arrumado" e passível de nos fornecer as tais leis universais, mas se interessa pelas conexões, pelas articulações e alianças dos elementos híbridos que compõem a rede. Dessa maneira, há uma contestação em relação às separações entre natureza e sociedade, sujeito e objeto, dentre outras, que o pensamento científico moderno propõe.

$E$, quando surgiu a oportunidade de escrever sobre psicologia e arte, este referencial latouriano pareceu possibilitar o interesse em abordar ambos os temas de maneira diferente do que há enquanto produção acadêmica que se propõe juntar ambos os temas. Ao invés de abordar aspectos cognitivos e psíquicos dos indivíduos em contato com a arte, o intuito foi, e é, o de falar do processo de produção artística e das consequências que este tem ao romper com um estilo dominante de tratar a arte, assim como as discussões que também pode suscitar no campo da Psicologia. Além da oportunidade de problematizar o que estamos fazendo e o que queremos com o que 
fazemos da Psicologia. Em outras palavras, o que Latour e seus aliados nos convidam, é pensar em nossas práticas e seus efeitos enquanto produção de mundos.

Ressalto que, no diálogo entre a proposta artística de Oiticica e as contribuições da teoria ator-rede, fica claro nas proposições deste artista seu interesse pela participação do público como um dos pontos cruciais de seu trabalho, assim como os atores do campo desempenham papel fundamental na teoria ator-rede. Todo esforço de Oiticica em instaurar uma nova maneira de fazer arte, que se desenvolve durante sua caminhada até chegar nas Manifestações ambientais, permite uma aproximação diferenciada do público com a obra, onde é necessária a relação de ambos para que a obra surja como tal. Entretanto, é interessante pensar que essa mudança na forma de conceber a arte produz outros efeitos, como por exemplo, a mudança na maneira de se comportar no museu. Este espaço tão marcado por uma série de regras e normas, ao receber as proposições de Oiticica vê uma desarrumação acontecer, pois onde a ordem era "não toque", agora é "toque", um convite feito por esse artista: "seja marginal!".

De igual modo, as proposições dos autores da teoria ator-rede preocupam-se com a colaboração dos atores do campo, os envolvidos no processo de conhecimento e feitura de trabalho. Há um entendimento de que o conhecimento é compartilhado, sendo tanto o pesquisador e os demais atores, todos responsáveis pelos conhecimentos produzidos. É importante ressaltar que nas linhas seguintes, muito falaremos do campo da pesquisa, pois estes autores influenciam o campo da Psicologia Social no que tange as práticas de pesquisa. Embora neste texto não seja usada exaustivamente a palavra psicólogo, este estará representado quando o termo pesquisador aparecer.

\section{Encontros}

Sobre o surgimento deste trabalho, faz-se necessário retomar uma vivência do primeiro período da faculdade, mais precisamente na aula de história da psicologia. Com todo ânimo peculiar de uma caloura, ouvia com atenção as explicações do professor, até que uma de suas frases me incomodou: não podemos falar em história da psicologia, mas das psicologias. O questionamento formado era o seguinte: como não podemos falar de uma única psicologia? Fato é, esta simples frase bagunçou minhas ideias a cerca deste campo do saber, entretanto, mantive em silêncio minhas indagações e desconfortos gerados por este posicionamento.

Passados alguns períodos, o ânimo inicial e a empolgação com o curso já não eram mais os mesmos. Embora o professor citado acima 
tenha dito que estamos num campo com muitas psicologias, aguardava que uma destas fizesse sentido para mim. Curioso que, o mesmo professor provocador de tanto desconforto, foi quem trouxe a luz essa psicologia que há tanto eu aguardava. Ao lecionar uma disciplina eletiva, cujo tema era Psicologia das emoções numa abordagem alternativa, provocava a cada aula novos questionamentos, outras indagações e perplexidade, no entanto, diferente do incômodo do primeiro período, experimentava agora a curiosidade.

Com a sequência das aulas, fui aceitando a possibilidade de ver meus conhecimentos sendo bagunçados por esta oportunidade de ver e entender a Psicologia, bem como suas práticas, de maneira diferente do que havia sido visto até então. Cabe ressaltar que, esta maneira alternativa não propõe a busca de um novo paradigma para a Psicologia, mas percebe outras possibilidades de fazer e pensar a Psicologia, sem contudo perderem a legitimidade.

Da mesma maneira que, o encontro com este professor e esta proposta de psicologia que foi apresentava em suas aulas possibilitou o surgimento deste tema de monografia e agora tema deste artigo, outro encontro permitiu sua consolidação: o encontro com as obras de Hélio Oiticica. Numa tarde como outra qualquer, o encontro se deu com a entrada no Centro Municipal de Arte Hélio Oiticica. Curiosamente, a exposição do local era "Hélio Oiticica: Penetráveis", contendo partes das obras deste artista, onde pudemos conhecer um pouco do que ele propunha.

Ao adentrarmos no local, fomos alertados sobre a possibilidade de tirarmos os sapatos para andar pelo local, se assim desejássemos. Embora soasse intrigante este convite, afinal, o museu visto como um lugar formal onde o silêncio e determinadas posturas precisam se valer, era só andar pelo local que logo entendíamos o porque desta convocação. O ambiente contava com areia e pedras compondo as instalações, bem como um espaço com revistas, palhas, espumas dentro de um retângulo de madeira, onde podíamos entrar e dispor da obra como desejássemos. Posteriormente descobri que se tratava de uma reprodução de Tropicália que Oiticica apresentou no Whitechapel Gallery.

Ao transitar pelo local e me surpreender com as proposições de tal artista e perceber no espaço do museu uma postura de convocação das obras a participar de sua feitura, percebi que esse contato me fez repensar uma série de coisas. Poder tocar nas obras, movimentá-las, encontrar no museu um espaço de liberdade e descoberta, afetou-me de forma a ampliar para o campo da Psicologia algumas das discussões pensadas e vivenciadas.

Aliado ao meu envolvimento com esta experiência, foi de grande importância ter vivenciado tudo isso com meu primo Maurício, que saiu do mesmo local que eu questionando tudo o que acabávamos de 
viver ali. Para ele, não podíamos dizer que "aquilo" era arte, pois em sua avaliação, somente contemplar um quadro com características evidentes da presença do belo poderia receber esse status de arte. Assim como ele tratava de definir o que é e o que não é arte, pensei na padronização que ocorre quando o assunto é ciência, quando é Psicologia. Sendo assim, tanto na monografia, como neste artigo, há uma proposta política forte: afirmar a legitimidade deste fazer artístico, bem como a legitimidade desta maneira alternativa de pensar e fazer pesquisa e Psicologia.

O trabalho de Hélio Oiticica é reconhecido internacionalmente e valorizado por sua importância, assim como a teoria ator-rede também tem seu reconhecimento e não precisam necessariamente de uma monografia ou um artigo para que sejam reconhecidos. Ao escrevê-los a intenção é de trazer à tona para o meio acadêmico a discussão da legitimidade ora negada a algumas propostas que não seguem os sedimentados padrões. Contudo, não há uma imaturidade de considerar que toda e qualquer proposta deva ser considerada como legítima, mas havendo possibilidade de reconhecimento e seriedade em suas proposições, a legitimidade não deve ser negada simplesmente por estar às margens dos padrões.

Em se tratando da teoria ator-rede, bem como as discussões do grupo de pesquisa do qual faço parte, este trabalho vem tratar de uma psicologia que tem suas bases numa Psicologia não moderna, ou seja, uma psicologia que não segue os paradigmas de uma Psicologia positivista, mas que pensa outros caminhos. Nesse sentido, John Law (2004) tratará da "bagunça no método" exatamente repensando as práticas de pesquisas e propondo um repensar quanto ao que é estritamente estabelecido e quase que proibido de ser questionado. Seguindo passos deste autor e de seus colegas, que serão citados ao longo do texto, é que um repensar a Psicologia será tecido.

\section{Caminhos para uma profanação}

Além da bagunça no meio artístico e na psicologia, há outro ponto em comum entre a arte proposta por Oiticica e a teoria ator-rede: é a potencialização do outro, seja espectador ou ator do campo. No caso de Hélio Oiticica um ponto primordial para o entendimento dos conceitos de suas obras é o caráter participativo que ele traz para sua produção artística. Essa participação se caracteriza pela inclusão do público na feitura da obra, o que por si só já serve de base para afirmar a bagunça na maneira de pensar e fazer arte que ele propõe. De início, um primeiro questionamento pode ser levantado: a única maneira de compreender uma obra como sendo artística é através do caráter contemplativo? Para quem tem uma resposta negativa para 
esta pergunta e ainda questiona o que pode ser possível para além deste caráter, Oiticica tem muito a contribuir.

Este artista permite que o público assuma uma certa coautoria na feitura de suas obras, mas, naturalmente, também incita um repensar o espaço do museu. Aquele museu onde a ordem é não tocar, ganha uma nova função ao receber o trabalho de Oiticica. Pensando que suas proposições necessitam da interação com o público, esse espaço se vê "bagunçado" e ganha novas funções, a ponto de poder ser explorado como antes não era permitido.

Não diferente de outros tantos artistas, Oiticica também teve seus momentos de descoberta da arte e uma apresentação aos quadros como um possível caminho artístico. Porém, devido ao seu envolvimento com o Grupo Frente e com o Movimento Neoconcreto, o rompimento com o quadro permanecia como sendo um ideal a ser seguido. Prova disso foi a entrevista dada por ele ao Jornal do Brasil em 1961, onde Oiticica relata: "Sinto que o quadro não satisfaz de forma alguma as necessidades de expressão do nosso tempo...o quadro é um espaço a priori - um retângulo, um suporte para a contemplação. É um elemento contemplativo por excelência" (Oiticica Filho, 2009, p. 21).

O momento histórico em que Oiticica se encontrava foi propício para que o fervilhar de ideias que ele tinha pudesse encontrar um terreno fértil e receptivo. Havia todo um movimento de crise da pintura e de desintegração do quadro. Embora no início de sua carreira ele tenha trabalhado com os Metaesquemas, que podem ser considerados como um quadro, já havia uma simpatia pela proposta de desintegração deste suporte. Sobre essa obra em específico, ele considera que não é nem quadro, nem pintura, pois:

(...) não é desenho a guache... pelo fato de eu não usar cor, usar pouca cor e usar o papelão, continua a ser pintura. Porque o espaço é pintura. Então Metaesquemas é isso: uma coisa que fica entre. Que não é nem pintura, nem desenho, mas na realidade uma evolução da pintura (Oiticica Filho, 2009, p. 265).

Suas obras começam a mostrar cada vez mais o seu salto. Com Invenções, a parede não é mais o fundo e o observador não pode mais entrar no interior do quadro, ao invés disso a cor encontra a sua liberdade do suporte. Para Favaretto (2000)

O monocromatismo e os efeitos de destacamento da parede, tentativas de anular a ação persistente do fundo e do suporte, liberam a cor como pulsação pura: limite extremo da pintura, mas não do plástico. A partir daí só há um caminho: sair para o espaço, soltar a cor. (ibidem, p.58) 
Os Bólides permitem que o espaço e a participação do público continuem ganhando força nas proposições de Oiticica, uma vez que - próprio artista considera, em entrevista concedida à revista "Artes", na Bienal de São Paulo em 1965, "Os Bólides requerem em geral a participação do espectador, que passa então a participador" (Oiticica Filho, 2009, p. 36). Portanto, com Oiticica há uma mudança no fazer artístico, mas também no espaço que recebe essas obras.

Todo esforço de Hélio será no sentido de promover manifestações artísticas que darão um caráter profano a arte, contrariando uma postura onde não se permite viver o espaço do museu com tamanha interação. Nesse sentido, Giorgio Agamben (2007) aponta para a noção de museificação do mundo, onde o espaço do museu fica marcado pela

(...) impossibilidade de usar (...) Museu não designa, nesse caso, um lugar ou um espaço físico determinado, mas a dimensão separada para a qual se transfere o que há um tempo era percebido como verdadeiro e decisivo, e agora já não é... De forma mais geral, tudo hoje pode tornar-se Museu, na medida em que esse termo indica simplesmente a exposição de uma impossibilidade de usar, de habitar, de fazer experiência. (Agamben, 2007, p.73)

Em resposta a essa museificação, um outro conceito de Agamben nos serve: a profanação, cuja ideia é a de restabelecer o uso daquilo que foi de certa forma privado de ser usado. Agamben (ibidem) aponta que uma das formas mais simples de profanação ocorre por meio do contágio, ou seja, é o toque que devolve ao uso aquilo que havia sido separado. No caso das proposições de Oiticica, esta profanação ocorre literalmente através do toque, o contato do público com a obra. De maneira geral, o trabalho de Oiticica tem o intuito de trazer diferentes elementos e maneiras de agir nesse espaço tão restrito a uma elite, onde este artista considera que há uma

barreira criada durante séculos de monopólio da "elite" sobre a arte; mas o inevitável está acontecendo: a derrubada desse monopólio e o descrédito das chamadas "elites sociais" e "intelectuais". Uma nova era, que chamo antiarte, está começando: é a era da grande participação popular no campo da criação. (Oiticica Filho, 2009, p. 42)

Esse convite de Agamben para a profanação, que relaciono como sendo o mesmo convite que Hélio nos faz, pode ser o mesmo entendido por outro autor, um poeta. Falo de Charles Baudelaire (2007), com seu texto "A perda da auréola". Essa história tão 
interessante conta que um determinado poeta, ao atravessar uma movimentada a rua, vê sua auréola cair na lama e ao invés de tentar reavê-la e correr o risco de ser atropelado, decide viver sem ela. Essa perda reserva ao poeta uma nova condição de vida: agora lhe é permitido frequentar lugares que antes um poeta jamais poderia frequentar. Agora, ele se torna um mortal como os outros.

Os efeitos da atitude deste poeta reflete na aproximação entre o artista e o público, um exercício que Hélio desenvolveu naturalmente, haja visto suas andanças pelo morro da Mangueira, muitas vezes sendo seu destino ao invés de frequentar as reuniões dos artistas da época (Oiticica Filho, 2009). E um dado interessante dessa relação que se estabelecia entre ele e os moradores da Mangueira é a influência que estes tinham na composição de suas obras. Muitas delas não apenas foram desenvolvidas a partir do seu convívio com a comunidade, como também tinham uma participação mais ativa em sua construção, como é o caso das capas Parangolé. Em uma entrevista concedida para a revista Cigarra, Oiticica (ibidem) afirma seu intuito em destruir o conceito de arte-artista, cuja visão concentrava a ideias de que não havia mais espaço para posições privilegiadas para "arte" e "artista", já não podendo mais pertencer unicamente a uma elite.

Ao buscar uma reflexão para a Psicologia a luz deste texto, proponho que pensemos a perda da auréola dos psicólogos, no sentido de abrir mão de um especialismo e de uma expertise soberana, para ao invés disso, dividir a responsabilidade do conhecimento. Sendo assim, primar por um saber "com" o outro e não "sobre" o outro. Isso implica numa postura de abandonar sua auréola, ou seja, abandonar seu pedestal para dar lugar a práticas de valorização do que o outro tem a compartilhar, não para encaixar nas teorias previamente estudadas, mas visando um aprender "com" aquele que também é dotado de conhecimento e que não devem ser desvalorizados ou renegados.

Tendo escolhido a teoria ator-rede para embasar esta postura de perda da auréola, confirmo a viabilidade desta relação por meio do entendimento de que a figura do pesquisador no campo, por exemplo, não é a de quem espera por ver suas perguntas respondidas integralmente. $O$ pesquisador, segundo a teoria atorrede, percorrerá os caminhos que o campo for mostrando serem válidos para a produção do conhecimento que se pretende. Para isso, as afetações entre o pesquisador, o campo, os atores, serão imprescindíveis. Sendo assim, não temos um pesquisador dotado de todo saber, que se empenha por revelar este conhecimento, mas um pesquisador que, junto com os atores que compõe a rede na qual estão imersos, entende que as realidades serão performadas pelo processo de relação entre eles. $E$, neste caminho de afetações, 0 outro (atores do campo) é visto como peça fundamental para que o 
conhecimento se dê, num processo de construção de saber compartilhado entre ambos.

Como dito anteriormente, Hélio Oiticica também preza pela participação ativa do público para que seu trabalho se torne uma obra. E, em um dos momentos que pude vivenciar durante um curso que fiz para aprender um pouco mais sobre a proposta artística de Hélio Oiticica, uma cena curiosa aconteceu e me serviu de inspiração e reflexão para entender o ponto crucial do que ele propunha: a participação do público.

\section{Parangolé-com-menino, menino-com-parangolé}

Pelos corredores do museu, um amontoado de Parangolé estava no chão, parecia que havia sido deixado despretensiosamente por algum visitante. Entretanto, ao desviar meu olhar para uma atividade que estava sendo realizada no espaço, o amontoado saiu da minha visão. Ao voltar meus olhos na direção deste, percebi que uma participante do curso havia abraçado aquela obra e, momentos depois, a obra se mexia. Para minha surpresa, um menino com seus 10 anos de idade se despia e dizia: eu era uma obra de arte.

Presenciar e relatar esta cena contribui para este trabalho, não apenas como um relato pessoal do que aconteceu no espaço do museu, mas com o intuito de também fundamentar essa afirmação da provocação que o trabalho de Oiticica evoca. Ao entrar em contato com o Parangolé, o público é convocado a se tornar obra, juntamente com o amontoado de panos que a compõe. Este envolvimento do público rompe com um certo caráter contemplativo em relação a maneira de se portar no museu. Segundo as proposições de Oiticica, a participação do público é imprescindível para que a obra seja vista como tal.

Seguindo um viés latouriano, pode-se dizer que é o encontro da obra com o público que faz dela obra, e deste, público. Como o próprio artista diz: "a participação de cada um é que dá sentido a obra". (Oiticica Filho, 2009, p. 44). Latour (1999) utiliza uma tirinha do cartunista argentino Quino para tratar de um assunto que se aproxima com o que está sendo falado a cerca deste encontro. Nesta tirinha, Mafalda vê seu pai sentado fumando um cigarro e pergunta o que ele está fazendo. Ele responde que está fumando e pergunta o porquê. Ela diz que não é nada, só tinha a impressão de que era o cigarro que estava fumando-o. Aparece então o pai desesperado se livrando dos cigarros.

Latour utiliza essa tirinha não para discutir que o controle está no cigarro (objeto) sobre o homem, mas para discutir que não há domínio de um sobre o outro, mas afetações que "fazem fazer", que convidam a ação. Dito de outra forma, não há domínio e nem ação 
simplesmente, há vínculos sendo formados a partir de determinados encontros em que os envolvidos se encontram potencializados.

De igual modo, Vinciane Despret (2004) faz referência ao trabalho de Lorenz e sua gralha, onde um jogo de relações acontece e permite que Lorenz se torne gralha e de igual modo, que a gralha se torne Lorenz. Ao trabalhar com este animal, Lorenz se dedica a conhecer este pássaro e vivenciar situações próprias de seu mundo. Assim como a gralha também passa por esse processo de viver o mundo de Lorenz. Cabe ressaltar que não se trata de um caso de antropomorfismo, nem de zoomorfismo, da mesma maneira que esse processo de transformação de Lorez e da gralha, apesar da ideia de empatia parecer presente, não é este o conceito ou mesmo o princípio abordado. Segundo Despret,

(...) empathy transforms the subject (the one who feels empathy) but this transformation is a very local one as long as it does not really give his object the chance to be activated as subject, the subject feeling empathy remaining the only subject of the whole thing (...) Empathy allows us to talk about what it is to be (like) the other, but does not raise the question 'what it is to be "with" the other'. (ibidem, p. 128)

Em vez disso, o que será discutido, nada mais é do que o ser "com" o outro. Embora neste caso Lorenz e a gralha sejam o foco, ser "com" o outro pode ser entendido de maneira mais abrangente, neste trabalho, na relação entre o público e a obra, o pesquisador e os atores que habitam o campo, o psicólogo e seu cliente. Mas para efeito de um entendimento maior sobre o caso de Lorenz e sua gralha, cabe expor um pouco desta relação.

Lorenz encontrou a gralha em um pet-shop e, afetado por ela, sentiu necessidade de alimentá-la. Para Despret, Lorenz agiu como se pertencesse àquela espécie e ele fez isso de uma maneira tão convincente que o animal foi capturado pelo jogo, e começou, depois de um tempo, a ver Lorenz como um membro de sua espécie que também precisava ser alimentado. (ibidem, p.129).

Lorenz estava interessado em entender como este animal se vincula a mãe e devido ao seu interesse, dispôs do seu corpo como dispositivo criado para entender este processo. Este pesquisador tem seu corpo usado como ferramenta para propor questões e criar relações. Desta forma, é criado um dispositivo que permite novas maneiras de coletar dados e o surgimento de novas práticas científicas. Como Despret coloca:

The experimenter, far from keeping himself in the background, involves himself: he involves his body, he involves his knowledge, his responsibility and his future. The practice of 
knowing has become a practice of caring. And because he cares for his young goose, he learns what, in a world inhabited by humans and geese, may produce relations (ibidem, p. 130)

Para a autora, eles domesticaram um ao outro, Lorenz não se tornou uma gralha, mas uma "gralha-com-humano", da mesma forma que tal animal se transformou em "humano-com-gralha". Ao entender o "com" como um salto a novas possibilidades de práticas, a permissão e a percepção da afetação encontra um terreno fértil para que outros elementos sejam considerados no processo de produção de conhecimento. $E$, relembrando a vivência com o menino e o Parangolé, citado anteriormente, temos uma relação de descoberta do mundo das obras, onde uma correlação pode ser feita a partir da participação ativa do menino com a obra: parangolé-com-menino e menino-com-parangolé.

Segundo esta versão exposta por Despret, o outro é entendido como parte importante, responsável sobre o conhecimento a ser produzido, o que faz desmontar a ideia de que haja um saber soberano que somente o pesquisador é capaz de descobrir. Seguindo essas pistas, a responsabilidade sobre o conhecimento será "com" o outro e não sobre o outro. E neste movimento de dividir a expertise, o outro é visto como interessante e capaz de promover conhecimento com suas ações. Com isso, esse posicionamento político-metodológico permite que haja espaço para mudanças ao longo do trabalho desenvolvido, reconhece que este não está livre de erros, de mal entendidos e assume esses riscos. E, mais especificamente sobre o mal entendido, quando surge, pode ser visto como promissor.

\section{Making a mess}

O mal-entendido promissor pode ser esclarecido tomando como base o trabalho de Marcia Moraes (2010) quando aborda sua experiência numa oficina de teatro com jovens e crianças cegos ou com baixa visão. Em uma de suas vivências com este grupo, Moraes (ibidem) presenciou um dilema de uma menina cega que interpretaria o papel de uma bailarina e era convocada a ter gestos leves, entretanto nunca vira tais gestos antes. Embora fossem dadas a ela orientações de como se portar, o que ela recebia, na verdade, eram referências de videntes e para ela era importante representar bem tanto para estes como para cegos, pois a plateia estaria composta por ambos.

Moraes é interpelada a intervir neste espaço de tensão, onde a menina era convocada a ser uma bailarina segundo referenciais dos videntes, mas ao mesmo tempo expressava não saber o que fazer por não entender o que estava sendo pedido e, assim, um mal entendido se instaurava. A partir de contribuições de Vinciane 
Despret, Moraes (ibidem) ressalta que o mal entendido promissor é aquele que abre possibilidades para aquilo que poderia estar aparentemente estável, permitindo e incitando a ver o outro não como passivo neste processo, respondendo apenas ao que the é solicitado, mas como um expert nesta relação, alguém ativo.

O trabalho desenvolvido por Jeanne Favret-Saada (2005) em seu texto "Ser afetado" expõe a ideia de afetação no campo em que faz parte. Favret-Saada se posiciona de maneira diferente dos antropólogos que também trabalham com a feitiçaria, segundo ela, estes ou se encontravam com as elites locais para saber sobre o assunto e/ou enviavam questionários interrogando alguns camponeses ou visavam a "observação-participante", interrogando e observando os eventos ligados a feitiçaria.

Favret-Saada privilegiará um ponto fundamental deixado de lado nestas duas abordagens: a palavra nativa. Segundo a autora, estas abordagens desqualificam esta palavra, mantendo a palavra do etnógrafo com todo o poder e saber, haja visto que sobre este tema a pesquisadora encontrou falas em que a feitiçaria era vista como o "cúmulo do atraso ou da imbecilidade" (ibidem). Decorrido estes episódios de desqualificação, as pessoas do Bocage (local onde a pesquisadora realizou sua pesquisa) resolveram não mais falar sobre o assunto com quem não se envolvesse de fato com os feitiços.

Sendo assim, o que permitiu o prosseguimento dos estudos de Favret-Saada foi o fato dos nativos considerarem que a pesquisadora foi "pega" pela feitiçaria. E nesse envolvimento com o que acontecia nesses eventos de feitiçaria ela foi construindo sua maneira de pesquisar. Pois ora se sentia no campo como etnógrafa, ora era convocada a participar pessoalmente destas experiências. FavretSaada comenta que:

No começo, não parei de oscilar entre esses dois obstáculos: se eu 'participasse', o trabalho de campo se tornaria uma aventura pessoal, isto é, o contrário de um trabalho; mas se tentasse 'observar', quer dizer, manter-me à distância, não acharia nada para 'observar'. (Favret-Saada, 2005, p. 157).

Favret-Saada comenta que se surpreendeu com as escolhas metodológicas que fez, pois durante a pesquisa ela não sabia bem o que estava fazendo, e que soube fazer dessa afetação um instrumento de conhecimento. Nos encontros com os enfeitiçados e desenfeitiçadores ela simplesmente se deixou afetar, deste modo, redigia numa espécie de diário de campo o que acontecia, para que posteriormente pudesse se organizar. A autora nos aponta que este diário de campo teve dois papéis principais: auxiliar na escrita do trabalho por meio de consulta a esses escritos e também acalmar a angustia da pesquisadora por ter se engajado com a feitiçaria. 
Cabe ressaltar que:

(...) quando um etnógrafo aceita ser afetado, isso não implica identificar-se com o ponto de vista nativo, nem aproveitar-se da experiência de campo para exercitar seu narcisismo. Aceitar ser afetado supõe, todavia, que se assuma o risco de ver seu projeto de conhecimento se desfazer. Pois se o projeto de conhecimento for onipresente, não acontece nada. Mas se acontece alguma coisa e se o projeto de conhecimento não se perde em meio a uma aventura, então a etnografia é possível. (Favret-Saada, 2005, p.160)

O texto de Moraes e de Favret-Saada revelam uma maneira diferente de estar no campo, onde os atores possuem um papel fundamental. O que pode ser visto como uma bagunça na maneira de fazer pesquisa, como diria Law (2006) em seu artigo "Making a mess with method", haja visto que altera partes dos procedimentos comumente realizado em pesquisa. Sobre isso, Law aponta em seu texto, que está interessado na bagunça, nos mundos bagunçados, nas políticas de bagunça, nos processos de conhecimento da bagunça. Law assume essa postura política por considerar que o mundo é bagunçado, por isso questiona práticas de pesquisa que tendem a ver o mundo de maneira clara e pura. Então, Law nos convidar a pensar práticas de pesquisa que se deem de maneira heterogênea e bagunçada, buscando conhecer a confusão e aprender a conviver com ela.

Em seu livro After method, Law (2004) faz a seguinte pergunta: Como pode o método lidar com a bagunça? Afinal, para ele "Se o mundo é complexo e confuso, então, pelo menos, algum momento vamos ter que desistir de simplicidades" (ibidem, p.2). E, como um alerta a essa questão, ele ressalta que uma vez aceito o desafio de pensar desta forma, teremos que ensinar a nós mesmos a pensar e conhecer de outra maneira. Law nos aponta que precisamos ensinar a nos mesmos a conhecer algumas realidades do mundo usando métodos incomuns ou desconhecidos em ciências sociais (ibidem, p.2).

Esta proposição de Law se dá por considerar que o mundo é complexo, assim como mencionado anteriormente, mas também como uma crítica ao apelo a padronização dos métodos, que ditam como estes devem ser. Law não pretende instituir novas regras, mas refletir maneiras diversas de agir na pesquisa, diferente das maneiras padronizadas. Ele diz o seguinte

Quero argumentar que, enquanto métodos padrão são extremamente bons no que fazem, eles são mal adaptados para o estudo do efêmero, do indefinido e do irregular. Como 
acabei de sugerir, isso implica que o problema não é tanto os próprios métodos de pesquisa padrão, mas o normatividades que estão ligados a eles em discursos sobre o método. Se é permitido 'métodos de investigação "para reivindicar a hegemonia metodológica ou (ainda pior) monopólio, e eu acho que há locais onde eles tentam fazer isso, então, quando são postas em relação com tais métodos que estão sendo colocados, porém rebelde, em um conjunto de restringir antolhos normativos. Estamos dizendo como devemos ver e o que devemos fazer incorporando suposições construídas no método ciência científico e social. (Law 2004, p.5-6)

Hélio Oiticica também passa por um processo semelhante ao criticar e subverter um determinado modo de ordenamento no fazer arte. Este artista, juntamente com o movimento neoconcreto promovem um repensar no fazer artístico que vinha sendo concebido como de maneira diferente do Grupo Ruptura, um grupo formado por artistas paulista e que se diziam legítimos representantes do concretismo.

O neoconcretismo surge com o grupo de artistas cariocas (Grupo Frente) a partir das divergências que estes tinham em relação as ideias do Grupo Ruptura, valorizando pontos considerados desvios da norma concretista. Um dos pontos privilegiados deste movimento será a postura de ter a experiência como gerador da obra, a obra não se limitará ao objeto. Este objeto transcendente, chamado de não objeto, não será mais tomado de forma isolada, mas será considerado como um objeto relacional. Sendo assim, o neoconcretismo nasce com a proposta de uma experiência corporal, não somente uma experiência visual. E, Hélio Oiticica fazendo parte desse processo de bagunça no fazer artístico, ao longo de sua trajetória foi desenvolvendo uma proposta singular, que teve sua expressão máxima dos expostos acima com suas Manifestações Ambientais.

As proposições de Law, segundo ele, vem de encontro a uma maneira criativa de responder ao mundo e reforça a necessidade do abandono da segurança, das certezas e garantias que tais padrões estabelecidos no campo das pesquisas pretendem pregar. E como ponto fundamental da crítica que Law faz, o que o autor chamará de "realismo euro-americano" terá um destaque especial. Law (2006), aponta que o "realismo euro-americano" acredita existir uma realidade única e independente de nossas ações, completamente anterior a nós. Neste caso, o real pode ser plenamente conhecido por um pesquisador, já que é um real delimitado, definido e preciso. Portanto, na pesquisa, ao se deparar com o que é confuso, a tendência segundo esta lógica é excluir este "invasor" do campo.

Contrapondo o "realismo euro-americano" Law (ibidem) afirmará que a realidade não está dada, mas é construída com as práticas. Sendo 
assim, o trabalho do pesquisador não será o de descrever uma realidade previamente dada, mas estar atento as práticas que são performadas e que fazem existir determinadas realidades. Compreender a realidade dessa forma desmonta a ideia de que um pesquisador pode captar uma realidade que está formada e este só precisa descrevê-la, representá-la. Este por si só já constitui um ponto de bagunça na maneira de compreender a pesquisa.

\section{Reflexões sobre o efeito efeito desta bagunça}

O presente trabalho tratou do tema da arte, e de uma maneira alternativa de pensar a pesquisa, a Psicologia, segundo um viés não moderno, ou seja, um certo afastamento de uma proposta calcada nos postulados positivistas, cartesianos e deterministas. Cabe reforçar que não há intenção de propor o estabelecimento de um novo paradigma. Ao contrário disso, o objetivo é dialogar com estas propostas e afirmar a legitimidade de outras formas de pensar, seja as manifestações artísticas de Helio Oiticica, e na Psicologia, as contribuições da teoria ator-rede.

Afirmar a legitimidade destas propostas e deste trabalho que está sendo escrito, fez-se parte fundamental, haja visto que uma pergunta perseguiu a escrita da monografia que inspira este artigo: onde está a Psicologia? Um questionamento vindo por parte de acadêmicos e leigos, que buscavam entender como seria possível um trabalho com este tema, principalmente quando está explícito que será um trabalho segundo uma Psicologia não moderna. Este ponto já se apresenta como uma questão intrigante, aliado a recusa de tomar a arte a partir de relações feitas ao processos cognitivos, ou relacionado ao aparelho psíquico e outros temas mais comuns na Psicologia.

Entretanto, apesar de muito ter sido falado nestas linhas, um ponto simples pode ser tomado como base: o questionamento e a reflexão sobre as práticas da Psicologia. Como dito na monografia que motivou a escrita deste artigo, talvez a pergunta não deva ser "onde está a Psicologia?", mas "Que Psicologia é essa que está diante de nós?", "Que Psicologia é essa (à) que $(\mathrm{m})$ temos feito?". (Lomba, 2001)

Muito embora não haja a pretensão de oferecer uma resposta universal que dê conta de responder a esta questão, pensar e refletir o que está sendo perguntado faz-se necessário. Aliás, este trabalho não tem se não o objetivo de fazer pensar práticas da psicologia que vem sendo desempenhadas e o que pode ser feito para além de uma Psicologia moderna. Com isso, pensar num trabalho cuja proposta é a de tratar a arte de maneira diferente do que é encontrado no campo da Psicologia, bem como aliar esta discussão a um questionamento de suas práticas, tem sua relevância confirmada não somente pela 
originalidade, mas pela importância de um debate diferenciado e fundamentado.

Sendo assim, destaco o tipo de escrita adotado para produzir este artigo como sendo uma aposta de autores ligados a teoria ator-rede, que adota essa proposta de trabalhar de certa forma com narrativas como uma postura política. Divulgamos em nossos escritos uma maneira diferente de pensar a Psicologia que vai sendo confirmada e difundida através, também, de uma escolha palavras e modos de escrever que contemplem toda busca por uma maneira diferente de fazer ciência. Se propomos pensar uma psicologia para além dos referenciais modernos e queremos atuar de maneira diferente, a maneira como nos relacionamos com nosso texto e com nosso leitor também ganha outros significados. Neste caso, uma escrita encarnada, que pode ser vista como pessoal, mas que deve ser entendida como uma escrita política.

Concluo reforçando que, monografias e artigos, assim como outros trabalhos acadêmicos, tem um papel importante para fomentar discussões que dizem respeito a Psicologia e suas práticas, revelando-se de extrema importância que produções interessantes e instigantes sejam produzidas a fim de enriquecer este campo. E, que artigos como este tenham este papel de divulgação de uma proposta de psicologia que contribua para o surgimento de novos questionamentos e que possibilite outros diálogos férteis.

\section{Referências}

Agamben, G (2007). Profanações. São Paulo: Boitempo Editorial.

Baudelaire, C. (2007). Pequenos poemas em prosa. São Paulo: Hedra. (A perda do Halo em 1865)

Despret, V. (2004). The body we care for: figures of anthropo-zoogenesis. Body and Society, 10(2-3), 112-132.

Favaretto, C. F. (2000). A invenção de Hélio Oiticica. São Paulo: Editora da Universidade de São Paulo.

Favret-Saada, J. (2005). Ser Afetado. Cadernos de Campo, 13(13), 155-161.

Latour, B. (2008). Reensamblar lo social: uma introdución a la teoria del actor-red. ( G. Zadunaisky, trad.), Buenos Aires: Manantial.

Latour, B. (2000). Ciência em ação: como seguir cientistas e engenheiros sociedade afora. (Benedetti, I.C., Trad.).São Paulo: UNESP, 2000.

Latour, B. (1999, Autumn). Fractures/fractures. From the concept of network to the concept of attachment. Factura, (36), 20-31. Recuperado em 29 abril, 2014, de http://www.brunolatour. fr/sites/default/files/downloads/76-FAKTURA-GB. pdf 
Latour, B. (1994). Jamais fomos modernos: Ensaio de Antropologia Simétrica.(C.I, Costa, Trad.) Rio de Janeiro: Editora 34.

Law, J. (2004). After method. Mess in social science research. London: Routledge.

Law, J. (2006). Making a mess with method. Recuperado em 29 abril, 2014, http://www. heterogeneities. net/publications/Law2006MakingaM esswithMethod.pdf

Lomba, D.E.N. (2011). Eu sou uma obra de arte, o museu é um mundo. Monografia de conclusão de curso de graduação em Psicologia, Universidade do Estado do Rio de Janeiro, Rio de Janeiro, RJ, Brasil.

Moraes, M. (2010). PesquisarCOM: política ontológica e deficiência visual. In M. Moraes, \& V. Kastrup (Orgs.). Exercícios de ver e não ver: arte e pesquisa com pessoas com deficiência visual (pp.26-51). Rio de Janeiro: Nau Editora.

Oiticica Filho, C., Cohn, S., \& Vieira, I. (2009). Hélio Oiticica. (Coleção Encontros). Rio de Janeiro: Beco do Azougue.

\section{Endereço para correspondência}

\section{Debora Emanuelle Nascimento Lomba}

Rua São Francisco Xavier, 524 10ㅇ andar sala 10.009 bloco F, Maracanã, CEP 20550-013, Rio de Janeiro - RJ, Brasil

Endereço eletrônico: deboralomba@gmail.com

Recebido em: 03/06/2014

Reformulado em: 24/11/2014

Aceito para publicação em: 07/12/2014

\section{Notas}

* Psicóloga formada pela Universidade do Estado do Rio de Janeiro - Mestranda PPGPS UERJ, Rio de Janeiro, RJ, Brasil. 